\title{
VITAMIN E INTAKE IN RELATION TO ALLERGIC SENSITIZATION AND IgE SERUM CONCENTRATION
}

\author{
Stefanie Sausenthaler ${ }^{1}$, Tobias Loebel ${ }^{1,2}$, Jakob Linseisen $^{2,3}$, Gabriele Nagel $^{3,4}$, Helgo Magnussen $^{5}$, Joachim Heinrich ${ }^{1}$ \\ ${ }^{1}$ Helmholtz Zentrum München, German Research Center for Environmental Health, Institute of Epidemiology, Neuherberg, Germany \\ ${ }^{2}$ Unit of Human Nutrition and Cancer Prevention, Technical University of Munich, Munich, Germany \\ ${ }^{3}$ Division of Clinical Epidemiology, German Cancer Research Center, Heidelberg, Germany \\ ${ }^{4}$ Institute of Epidemiology, Ulm University, Ulm, Germany \\ ${ }^{5}$ Pulmonary Research Institute at Grosshansdorf Hospital, Center for Pneumology and Thoracic Surgery, Grosshansdorf, Germany
}

\begin{abstract}
SUMMARY
Background: A protective role of dietary vitamin E intake on disorders related to the immune system, such as allergic diseases, has been suggested. However, results from epidemiological studies are conflicting.

Objectives: The aim of present study was to analyze whether dietary vitamin $\mathrm{E}$ intake is related to the prevalence of allergic sensitization and total serum IgE concentrations in adult subjects.

Methods: The present study population consisted of 366 adults aged 29 to 54 years participating in the German centers of the European Community Respiratory Health Survey (ECRHS) II, Erfurt and Hamburg. A validated food frequency questionnaire was used to gather information on dietary vitamin $E$ intake. Total serum IgE concentrations and specific $\mathrm{Ig} E$ to common allergens were analyzed by using the Pharmacia CAP System. Allergic sensitization was defined as specific serum IgE concentration $\geq 0.35 \mathrm{kU} /$.

Results: The risk for allergic sensitization was substantially decreased in the middle quartiles (aOR: $0.42 ; 95 \% \mathrm{Cl}: 0.22-0.81$ ) and the highest quartile (aOR: $0.22 ; 95 \% \mathrm{Cl}: 0.08-0.60$ ) of total dietary vitamin $\mathrm{E}$ intake, after adjustment for potential confounders. Total serum IgE concentration was not statistically significantly associated with dietary vitamin $E$ intake.

Conclusions: The findings of this study suggest that dietary vitamin E intake might play a protective role in the development of allergic sensitization.
\end{abstract}

Key words: adults, allergic sensitization, a-tocopherol, dietary vitamin E, ECRHS II, immunoglobulin E

Address for correspondence: S. Sausenthaler, Helmholtz Zentrum München, German Research Center for Environmental Health, Institute of Epidemiology, Ingolstaedter Landstr. 1, 85764 Neuherberg, Germany. E-mail: s.sausenthaler@helmholtz-muenchen.de

\section{INTRODUCTION}

Recent research on the etiology of the increasing prevalence rates of asthma and allergy also considers dietary factors that are typical for a western lifestyle. Among the changing composition of the diet during the past decades, a decreased intake of fresh fruit and vegetables were discussed to play a role in the development of allergic sensitization and allergic diseases (1-3). Vitamin and antioxidant deficiency has mainly been thought to underlie these observations. One focus was put on the intake of vitamin $\mathrm{E}$ as epidemiological studies were demonstrating beneficial associations between dietary vitamin $\mathrm{E}$ intake and hay fever (4), wheeze (5-7) and asthma (8-10). However, supplementation with different forms of vitamin $\mathrm{E}$ was often not effective in clinical trials $(11,12)$. Therefore, the interest on the potential role of dietary vitamin E on allergy manifestation has diminished rapidly. Given that the presence of elevated serum levels of immunoglobulin $\mathrm{E}$ (IgE) are known to be fundamental to type I allergic reactions and can be synthesised even before clinical symptoms occur, it might be worthwhile to pay more attention to early markers of allergy such as IgE.

While great attention has been paid to the antioxidative capacity of vitamin $\mathrm{E}$ in the past $(13,14)$, based on the findings from experimental studies in animals and humans, the potential biological mechanisms of vitamin $\mathrm{E}$ on IgE production are mainly those exerted on Thelper cell differentiation and on regulatory functions in eicosanoid production. In vitro, vitamin $\mathrm{E}$ increases Thelper 1 (Th1) cytokine secretion and inhibits T helper 2 (Th2) cytokine secretions $(15,16)$. Vitamin E also reduces interleukin-4 (IL-4) secretion in human peripheral blood T-cells in a dose dependent manner (17). As IL-4 promotes the production of IgE antibodies by B-cells, it is one of the key cytokines in the development of allergic inflammation. Furthermore, an inhibitory effect of vitamin $\mathrm{E}$ on the activity of cyclooxygenase, a major enzyme for eicosanoid synthesis, particularly arachidonic acid-derived prostaglandin $\mathrm{E}_{2}\left(\mathrm{PGE}_{2}\right)$, has been reported (18). In turn, $\mathrm{PGE}_{2}$ has been implicated in shifting the balance of Th1/Th2 cells and their cytokines towards a Th2 profile (19). Overall, evidence from experiments suggests that vitamin E might be protective against the development of allergic sensitization.

Accordingly, Fogarty et al. (20) reported that higher concentrations of vitamin E intake were associated with lower serum IgE concentrations and a lower frequency of allergic sensitization. In contrast, other studies measuring dietary vitamin E intake (21) or plasma concentrations of vitamin E $(22,23)$ did not find any effect on sensitization. Although there is some indication that vitamin 
Table 1. Characteristics of the study population (ECRHS II) ${ }^{1}$

\begin{tabular}{|c|c|c|c|c|}
\hline & \multicolumn{2}{|c|}{ Men ( $N=186)$} & \multicolumn{2}{|c|}{ Women $(\mathrm{N}=180)$} \\
\hline & $\mathrm{n}$ & $\%$ & $\mathrm{n}$ & $\%$ \\
\hline \multicolumn{5}{|l|}{ Study center } \\
\hline Erfurt & 92 & 49.5 & 92 & 51.1 \\
\hline Hamburg & 94 & 50.5 & 88 & 48.9 \\
\hline \multicolumn{5}{|l|}{ Age group } \\
\hline $30-39$ years $^{2}$ & 67 & 36.0 & 65 & 36.1 \\
\hline 40-49 years & 77 & 41.4 & 74 & 41.1 \\
\hline $50-54$ years & 42 & 22.6 & 41 & 22.8 \\
\hline \multicolumn{5}{|l|}{ Occupation } \\
\hline Employed & 132 & 71.0 & 134 & 74.4 \\
\hline Self-employed & 33 & 17.7 & 8 & 4.4 \\
\hline Non-employed & 21 & 11.3 & 38 & 21.1 \\
\hline \multicolumn{5}{|l|}{ Smoking status } \\
\hline Current smoker & 61 & 32.8 & 46 & 25.6 \\
\hline Former smoker & 74 & 39.8 & 58 & 32.2 \\
\hline Never smoker & 51 & 27.4 & 76 & 42.2 \\
\hline \multicolumn{5}{|c|}{ Physical Activity (hours/week) } \\
\hline Inactive (0) & 59 & 31.7 & 72 & 40.2 \\
\hline Semi-active (0.5-3) & 90 & 48.4 & 93 & 52.0 \\
\hline Active $(\geq 4)$ & 37 & 19.9 & 14 & 7.8 \\
\hline
\end{tabular}

${ }^{1}$ European Community Respiratory Health Survey II

${ }^{2}$ Two individuals with age 29 years

E might reduce IgE concentrations, findings are conflicting and consequently the potential benefit of vitamin $\mathrm{E}$ intake still needs to be clarified.

Therefore, the aim of present study was to analyze the association of dietary vitamin E intake with allergic sensitization and total serum IgE concentration in a population-based sample of adult subjects.

\section{MATERIAL AND METHODS}

\section{Study Subjects and Study Design}

The present study is based on subjects participating in the German part of the European Community Respiratory Health Survey (ECRHS) II. The population sample comprised adults aged 29 to 54 years from the German cities Hamburg and Erfurt. Study design and population sampling have been described in detail elsewhere (24). In brief, subjects taking part in ECRHS I in 1991-1992, were re-contacted for the follow-up in 2000-2001. A total of 1,216 subjects (75.3\%) of the 1,615 subjects invited to the study agreed to participate. The remaining 399 subjects either could not be traced $(n=247)$, refused further participation $(n=28)$, moved out of the area $(n=110)$ or died $(n=14)$. The follow-up included an extensive interviewer administered questionnaire, lung function measurement and blood sampling for IgE analysis. In addition, a subsample of 390 subjects completed a food frequency questionnaire (FFQ). Present analysis is restricted to 366 subjects with complete data on diet, total and specific IgE.

The study protocol was approved by the local ethics committees.

\section{Dietary Assessment}

Information on dietary intake was gathered by means of a validated semiquantitative FFQ (25-27) including 158 food items, which was originally designed for the German part of the European Prospective Investigation into Cancer and Nutrition (EPIC-Heidelberg). Nutrient intake data were calculated from the food intake data based on the German Food Composition Tables BLS Version II.3 (Bundeslebensmittelschlüssel, Bg VV, Berlin, Germany, 1999).

\section{Blood Samples}

Blood samples were collected for the measurement of serumspecific IgE and total IgE using the Pharmacia CAP System (Pharmacia Diagnostics, Uppsala, Sweden). Serum samples were stored at $-20^{\circ} \mathrm{C}$ and then transferred to a central laboratory in London, where they were tested for specific IgE to house dust mite, grass, cat, Cladosporium and total IgE. Allergic sensitization was defined as specific serum IgE concentration $\geq 0.35 \mathrm{kU} / \mathrm{l}$ (RAST class $\geq 1$ ) against at least one of the tested allergens. 
Table 2. Vitamin E, vitamin $C$ and energy intake in the study population

\begin{tabular}{|l|c|c|c|c|c|c|c|c|c|c|}
\hline & \multicolumn{4}{|c|}{ Men (N=186) } & \multicolumn{5}{c|}{ Women (N=180) } \\
\hline Intake & $\mathbf{G M}^{1}$ & $\mathbf{G S D}^{2}$ & Q1 & Q2 & Q3 & GM $^{1}$ & GSD $^{2}$ & Q1 & Q2 & Q3 \\
\hline Vitamin E (mg/d) & 9.3 & 1.4 & 7.4 & 9.1 & 11.9 & 8.1 & 1.4 & 6.4 & 7.9 & 10.0 \\
\hline Vitamin E (mg/1,000 kcal) & 3.7 & 1.3 & 3.2 & 3.7 & 4.3 & 4.3 & 1.3 & 3.7 & 4.3 & 5.0 \\
\hline Vitamin C (mg/d) & 103 & 1.6 & 74 & 95 & 133 & 107 & 1.6 & 78 & 108 & 148 \\
\hline Energy (kcal/d) & 2,520 & 1.4 & 1,995 & 2,457 & 3,079 & 1,862 & 1.4 & 1,501 & 1,840 & 2,240 \\
\hline Fat energy (\% of energy intake) & 907 & 1.5 & 714 & 894 & 1,169 & 684 & 1.4 & 532 & 676 & 856 \\
\hline
\end{tabular}

${ }^{1}$ Geometric mean

${ }^{2}$ Geometric standard deviation

\section{Statistical methods}

Sex-specific quartiles were calculated for total and energy-adjusted vitamin $\mathrm{E}$ ( $\alpha$-tocopherol) intake in $\mathrm{mg} / \mathrm{d}$ and $\mathrm{mg} / 1,000 \mathrm{kcal}$, respectively. Multiple logistic regression analyses were applied to estimate the association between dietary intake of vitamin $\mathrm{E}$ and allergic sensitization and total serum IgE concentration, respectively. To transfer total serum IgE concentration into a binary outcome variable, arbitrarily selected cut-off points at $100 \mathrm{kU} / \mathrm{l}$ and $180 \mathrm{kU} / \mathrm{l}$ were used. Odds ratios (OR) with corresponding 95\% confidence intervals (CI) were computed for the combined second and third quartile (Q2-Q3) and the highest quartile (Q4) of vitamin E intake compared to the first quartile (Q1). The associations were adjusted for an a priori selected set of confounders including study center, sex, age group, occupation, smoking status and physical activity. Furthermore, we calculated a model additionally adjusted for vitamin $\mathrm{C}$ intake, and one additionally adjusted for vitamin $\mathrm{C}$ and fat energy intake.

All computations were performed using the statistical analysis package SAS for Windows version 9.1 (SAS Institute, Cary, NC, USA). Two-sided p-values $<0.05$ were considered statistically significant in all analyses.

\section{RESULTS}

Basic characteristics of the study population are presented in Table 1. About half of the subjects lived in Erfurt, while the other half lived in the study area of Hamburg. The mean age of men and women was 43.0 and 42.7 years, respectively. Participants of both sexes were mainly employed, but less women than men were self-employed. Men were also more likely smokers or former smokers compared to women. High physical activity defined as being active for at least 4 hours per week seemed to be more prevalent in men compared to women.

The geometric mean (GM) of total vitamin $E$ intake was $9.3 \mathrm{mg} / \mathrm{d}$ in men and $8.1 \mathrm{mg} / \mathrm{d}$ in women, but energy-adjustment showed that vitamin E density was slightly higher in females than in males (Table 2). Total vitamin C intake did not differ substantially between male and female subjects. Total energy intake was higher in men compared to women, but the percentage of energy derived from fat intake was similar in both sexes with about $36 \%$.

The prevalence of allergic sensitization according to sex-specific quartiles of vitamin $\mathrm{E}$ intake is shown in Table 3. The risk

Table 3. Prevalence of allergic sensitization in relation to vitamin E intake in the study population

\begin{tabular}{|c|c|c|c|c|}
\hline \multirow[b]{3}{*}{ Intake ${ }^{2}$} & \multicolumn{4}{|c|}{ Allergic sensitization $^{1}$} \\
\hline & \multicolumn{2}{|c|}{ Men (N=186) } & \multicolumn{2}{|c|}{ Women $(\mathrm{N}=180)$} \\
\hline & $\mathrm{n} / \mathrm{N}$ & $\%$ & $\mathrm{n} / \mathrm{N}$ & $\%$ \\
\hline \multicolumn{5}{|c|}{ Vitamin E (mg/d) } \\
\hline Q1 & $21 / 46$ & 45.7 & $16 / 45$ & 35.6 \\
\hline Q2-Q3 & $32 / 94$ & 34.0 & $23 / 90$ & 25.6 \\
\hline Q4 & $11 / 46$ & 23.9 & $10 / 45$ & 22.2 \\
\hline \multicolumn{5}{|c|}{ Vitamin E (mg/1,000 kcal) } \\
\hline Q1 & $16 / 46$ & 34.8 & $18 / 45$ & 40.0 \\
\hline Q2-Q3 & $33 / 94$ & 35.1 & $21 / 90$ & 23.3 \\
\hline Q4 & $15 / 46$ & 32.6 & $10 / 45$ & 22.2 \\
\hline
\end{tabular}

${ }^{1}$ At least one specific $\lg \mathrm{E} \geq 0.35 \mathrm{kU} / \mathrm{l}$

${ }^{2}$ Sex-specific quartiles 
Table 4. Total IgE serum concentration in relation to vitamin E intake in the study population

\begin{tabular}{|c|c|c|c|c|}
\hline \multirow[b]{3}{*}{ Intake ${ }^{1}$} & \multicolumn{4}{|c|}{ Total IgE (kU/l) } \\
\hline & \multicolumn{2}{|c|}{ Men (N=186) } & \multicolumn{2}{|c|}{ Women (N=180) } \\
\hline & $\mathrm{GM}^{2}$ & $\mathrm{GSD}^{3}$ & $\mathbf{G M}^{1}$ & GSD $^{2}$ \\
\hline \multicolumn{5}{|c|}{ Vitamin E (mg/d) } \\
\hline Q1 & 50.9 & 3.0 & 35.1 & 4.1 \\
\hline Q2-Q3 & 42.9 & 3.9 & 32.6 & 3.5 \\
\hline Q4 & 43.6 & 4.0 & 29.1 & 4.0 \\
\hline \multicolumn{5}{|c|}{ Vitamin E (mg/1,000 kcal) } \\
\hline Q1 & 47.7 & 3.8 & 38.2 & 3.5 \\
\hline Q2-Q3 & 51.2 & 3.7 & 31.3 & 3.8 \\
\hline Q4 & 32.4 & 3.3 & 28.9 & 3.8 \\
\hline
\end{tabular}

${ }^{1}$ Sex-specific quartiles

${ }^{2}$ Geometric mean

${ }^{3}$ Geometric standard deviation

for allergic sensitization continuously decreased with increasing total vitamin $\mathrm{E}$ intake in both men and women. For energy-adjusted vitamin $\mathrm{E}$ intake, the association was less clear. The geometric mean of total serum IgE concentration was $44.9 \mathrm{kU} / \mathrm{l}$ and $32.2 \mathrm{kU} / \mathrm{l}$ in men and women (data not shown), respectively. In women, the lowest vitamin $\mathrm{E}$ or energy-adjusted vitamin $\mathrm{E}$ intakes were associated with the highest total IgE concentration (Table 4). This relationship was not observed in men.

Results of the logistic regression models are shown in Table 5 and Table 6. Total vitamin $\mathrm{E}$ intake in the highest quartile was inversely associated with allergic sensitization in the crude model. After adjustment for study center, sex, age group, occupation, smoking status and physical activity, the magnitude of the association was not substantially altered. However, when vitamin
C intake was additionally included in the model, risk estimates strongly decreased. Further adjustment for fat energy intake did not substantially alter the effect estimates. The results for energyadjusted vitamin $\mathrm{E}$ intake were similar but not as strong as for total vitamin E intake before and after controlling for potential confounders. There were no consistent significant associations found between vitamin $\mathrm{E}$ intake and total serum IgE concentration (Table 6). Although the odds of serum IgE concentration greater than $100 \mathrm{kU} / \mathrm{l}$ seemed to decrease from the lowest to the highest quartile of vitamin E intake, it did, however, not reach statistical significance. Similar results were obtained when the cut-off point was set at $180 \mathrm{kU} / \mathrm{l}$ (data not shown).

Table 5. Crude and adjusted logistic regression results describing the association between quartiles of vitamin $E$ intake and allergic sensitization ${ }^{1}$ in the study population

\begin{tabular}{|c|c|c|c|}
\hline & Q1 & Q2-Q3 & Q4 \\
\hline Intake & OR & OR (95\% Cl) & OR (95\% Cl) \\
\hline \multicolumn{4}{|c|}{ Vitamin E (mg/d) } \\
\hline $\mathrm{OR}^{2}$ & 1.00 & $0.62(0.37-1.05)$ & $0.44(0.23-0.83)^{6}$ \\
\hline $\mathrm{aOR}^{3}$ & 1.00 & $0.56(0.33-0.97)^{6}$ & $0.40(0.21-0.77)^{6}$ \\
\hline $\mathrm{aOR}^{4}$ & 1.00 & $0.47(0.26-0.86)^{6}$ & $0.26(0.12-0.60)^{6}$ \\
\hline $\mathrm{aOR}^{5}$ & 1.00 & $0.42(0.22-0.81)^{6}$ & $0.22(0.08-0.60)^{6}$ \\
\hline \multicolumn{4}{|c|}{ Vitamin E (mg/1,000 kcal) } \\
\hline $\mathrm{OR}^{2}$ & 1.00 & $0.70(0.41-1.18)$ & $0.64(0.34-1.19)$ \\
\hline $\mathrm{aOR}^{3}$ & 1.00 & $0.64(0.36-1.11)$ & $0.51(0.26-1.00)$ \\
\hline $\mathrm{aOR}^{4}$ & 1.00 & $0.61(0.34-1.10)$ & $0.48(0.23-0.98)^{6}$ \\
\hline $\mathrm{aOR}^{5}$ & 1.00 & $0.58(0.32-1.04)$ & $0.39(0.18-0.83)^{6}$ \\
\hline
\end{tabular}

${ }^{1}$ At least one specific $\lg \mathrm{E} \geq 0.35 \mathrm{kU} / \mathrm{l}$

${ }^{2}$ Crude odds ratios

${ }^{3}$ Odds ratios adjusted for study area, sex, age group, occupation, smoking status, physical activity

${ }^{4}$ Odds ratios adjusted for study area, sex, age group, occupation, smoking status, physical activity and vitamin $\mathrm{C}$ intake

${ }^{5}$ Odds ratios adjusted for study area, sex, age group, occupation, smoking status, physical activity, vitamin $\mathrm{C}$ intake and fat energy intake ${ }^{6} \mathrm{p}<0.05$ 
Table 6. Crude and adjusted logistic regression results describing the association between quartiles of vitamin E intake and total IgE serum concentration ${ }^{1}$ in the study population

\begin{tabular}{|c|c|c|c|}
\hline & Q1 & Q2-Q3 & Q4 \\
\hline Intake & OR & OR $(95 \% \mathrm{Cl})$ & OR ( $95 \% \mathrm{Cl})$ \\
\hline \multicolumn{4}{|c|}{ Vitamin E (mg/d) } \\
\hline $\mathrm{OR}^{2}$ & 1.00 & $0.78(0.43-1.44)$ & $1.00(0.50-1.99)$ \\
\hline $\mathrm{aOR}^{3}$ & 1.00 & $0.84(0.45-1.57)$ & $1.05(0.52-2.12)$ \\
\hline $\mathrm{aOR}^{4}$ & 1.00 & $0.72(0.36-1.44)$ & $0.68(0.28-1.66)$ \\
\hline $\mathrm{aOR}^{5}$ & 1.00 & $0.57(0.27-1.23)$ & $0.48(0.16-1.41)$ \\
\hline \multicolumn{4}{|c|}{ Vitamin E (mg/1,000 kcal) } \\
\hline $\mathrm{OR}^{2}$ & 1.00 & $1.12(0.61-2.07)$ & $0.81(0.39-1.69)$ \\
\hline $\mathrm{aOR}^{3}$ & 1.00 & $1.09(0.58-2.06)$ & $0.78(0.36-1.68)$ \\
\hline $\mathrm{aOR}^{4}$ & 1.00 & $0.96(0.49-1.87)$ & $0.60(0.26-1.40)$ \\
\hline $\mathrm{aOR}^{5}$ & 1.00 & $0.96(0.49-1.87)$ & $0.59(0.25-1.40)$ \\
\hline
\end{tabular}

${ }^{1}>100 \mathrm{kU} / \mathrm{l}$

${ }^{2}$ Crude odds ratios

${ }^{3}$ Odds ratios adjusted for study area, sex, age group, occupation, smoking status, physical activity

${ }^{4}$ Odds ratios adjusted for study area, sex, age group, occupation, smoking status, physical activity and vitamin $\mathrm{C}$ intake

${ }^{5}$ Odds ratios adjusted for study area, sex, age group, occupation, smoking status, physical activity, vitamin $\mathrm{C}$ intake and fat energy intake

\section{DISCUSSION AND CONCLUSIONS}

The findings of this study suggest dietary intake of vitamin $\mathrm{E}$ is inversely associated with allergic sensitization in adults. However, there was no statistically significant association between vitamin E intake and total IgE serum concentration.

These observations are similar to those reported by Fogarty et al. (20), who investigated the relationship between dietary vitamin E intake and serum IgE concentration and atopy, measured by skin prick test (SPT), in a random sample of 2,633 adults aged 18-70 years. Higher concentrations of vitamin $\mathrm{E}$ intake were associated with lower serum IgE concentrations and a lower frequency of allergic sensitization in this study. Another cross-sectional study did not detect any association between dietary vitamin E intake and atopy assessed by SPT (21).

Considering that allergic diseases are frequently characterized by raised serum IgE concentrations and sensitization to common allergens, our results are indirectly supported by previous epidemiological studies reporting beneficial associations of dietary vitamin E intake with clinical manifestations of allergy, asthma and asthma-related phenotypes (4-10). Some of these studies have investigated the effect of prenatal exposure to vitamin $\mathrm{E}$ on eczema (6, 7), wheezing (6-8) and asthma (8) in childhood. Recently, Martindale et al. (7) reported that maternal vitamin E intake during pregnancy is negatively associated with wheezing in the absence of a cold and eczema in the offspring during the first two years of life. Further follow-up of the cohort showed that low maternal vitamin E intake during pregnancy was also associated with persistent wheezing and persistent asthma up to 5 years of age (8). More evidence is provided by Litonjua et al. (6), who demonstrated an inverse association between maternal intake of vitamin E during pregnancy and wheezing but not eczema in 2-year-old children. More evidence is provided by cross-sectional studies. Within the framework of the Nurses' Health Study, it has been reported that the incidence of asthma was negatively associated with dietary vitamin E intake (10). Women in the highest quintile of vitamin $\mathrm{E}$ intake from diet had a $47 \%$ lower risk for asthma than had women in the lowest quintile. However, vitamin E intake from supplements seemed to be related to an increased asthma risk in this study. The authors suggested that this association is probably due to asthmatic women who started to take vitamin supplements after the onset of symptoms. Furthermore, they demonstrated that exclusion of dietary vitamin $\mathrm{E}$ intake from nuts and peanut butter attenuated this association. The authors considered a possible bias due to asthmatic subjects avoiding food allergens. Dietary vitamin E intake in relation to hay fever risk has been investigated in the EPIC-Heidelberg cohort using data from 334 cases and 1,336 controls (4). A decreased risk of hay fever with increasing vitamin $\mathrm{E}$ intake has been described, by using the identical FFQ as in present study. Further cross-sectional studies have demonstrated negative associations between dietary vitamin E intake and adult-onset wheeze (5) and childhood asthma (9) and one did not detect any association with asthma or atopy (21). Some authors studied tocopherol plasma concentrations as a marker of vitamin $\mathrm{E}$ bioavailability in relation to atopy. In this way, increasing blood concentrations of vitamin $E$ were associated with a slightly reduced risk of allergic sensitization assessed by SPT in a large US study population (23). However, in a German cross-sectional study, allergic sensitization assessed by specific IgE measurement was negatively associated with plasma $\gamma$-tocopherol, but not with plasma $\alpha$-tocopherol (28).

Several possible limitations of the study need to be considered. One weakness of the study is due to the cross sectional design as dietary intake and serum IgE concentrations were measured at the same point in time. Allergic sensitization is thought to be primed in early childhood and is potentially followed by clinical manifestations of allergic diseases later in life. However, longitudinal 
analyses have demonstrated changes in specific IgE antibody concentrations over time (29). Therefore, we speculate that vitamin E intake during the last 12 months prior to the blood measurement may contribute to differences in serum IgE concentrations and allergic sensitization observed between study participants. Unfortunately, the number of subjects in our study was too small to study asthma and hay fever. To verify the cause-effect relationship of our findings, longitudinal studies should be conducted. We also cannot completely rule out that the assessment of dietary vitamin $\mathrm{E}$ intake is afflicted with some measurement error due to lacking information on vitamin supplementation. As random misclassification of intake would tend to attenuate associations, it is unlikely that misclassification bias has lead to spurious associations. Reverse causation is a further potential source of bias. Reverse causation might be only a problem in symptomatic subjects. However, when excluding subjects with hay fever or asthma from the analysis, the protective effect of high intake of vitamin E remained. In addition, the food frequency questionnaire used in present study has already been validated by comparison with 24-hour dietary recall in a pilot study in the German part of the EPIC cohort (25). The adjusted correlation coefficient of dietary vitamin $\mathrm{E}$ intake between both instruments was 0.45 and thus in an acceptable range compared to other nutrients. Thus, estimates of vitamin E intake derived from FFQ seem to reflect habitual intake over a large period satisfactorily. In attempt to reduce the effect of confounding bias, associations were adjusted for the covariates study center, sex, age group, occupation, smoking status, physical activity, vitamin $\mathrm{C}$ intake and fat energy intake. The odds ratios were substantially lowered when vitamin $C$ intake was included in the model, which indicates confounding by vitamin $\mathrm{C}$ intake. Although testing for interaction between vitamin $\mathrm{E}$ and vitamin C was not statistically significant, a possible synergistic effect of vitamin $\mathrm{E}$ with other nutrients, which has been demonstrated in vivo (30) and in vitro (31), should not be ignored. However, effect estimates for the crude association between vitamin $\mathrm{C}$ intake and allergic sensitization and total IgE concentration were not statistically significant.

In conclusion, present study provides further evidence for a beneficial effect of dietary vitamin $\mathrm{E}$ intake on allergic sensitization. However, prospective studies should be performed to verify the cause-effect relation.

\section{Acknowledgement}

The authors gratefully acknowledge the fieldworkers Marion Muecke (Hamburg) and Gabriele Wölke (Erfurt), Christina Luczynska for IgE measurements (Kings College London) and Gabi Bolte for supervision fieldwork of the dietary survey.

SS and TL were responsible for data analysis, interpretation of data and manuscript preparation. JL, GN, HM and JH assisted in the interpretation of results and critical revision of the manuscript. JH initiated this study and is PI of the German ECRHS study centers. None of the authors had any conflict of interest.

This study was supported by the German Research Foundation (DFG) contract numbers FR 1526/1-1, HE 3294/1-1 and HE 3294/3-1.

\section{REFERENCES}

1. Devereux G, Seaton A. Diet as a risk factor for atopy and asthma. J Allergy Clin Immunol. 2005 Jun;115(6):1109-17.
2. Fogarty A, Britton J. The role of diet in the aetiology of asthma. Clin Exp Allergy. 2000 May;30(5):615-27.

3. Heinrich J, Hölscher B, Bolte G, Winkler G. Allergic sensitization and diet: ecological analysis in selected European cities. Eur Respir J. 2001 Mar;17(3):395-402.

4. Nagel G, Nieters A, Becker N, Linseisen J. The influence of the dietary intake of fatty acids and antioxidants on hay fever in adults. Allergy. 2003 Dec;58(12):1277-84.

5. Bodner C, Godden D, Brown K, Little J, Ross S, Seaton A; Aberdeen WHEASE Study Group. Antioxidant intake and adult-onset wheeze: a case-control study. Eur Respir J. 1999 Jan;13(1):22-30.

6. Litonjua AA, Rifas-Shiman SL, Ly NP, Tantisira KG, Rich-Edwards JW, Camargo CA Jr, et al. Maternal antioxidant intake in pregnancy and wheezing illnesses in children at 2 y of age. Am J Clin Nutr. 2006 Oct;84(4):903-11.

7. Martindale S, McNeill G, Devereux G, Campbell D, Russell G, Seaton A. Antioxidant intake in pregnancy in relation to wheeze and eczema in the first two years of life. Am J Respir Crit Care Med. 2005 Jan 15;171(2):121-8.

8. Devereux G, Turner SW, Craig LCA, McNeill G, Martindale S, Harbour $\mathrm{PJ}$, et al. Low maternal vitamin $\mathrm{E}$ intake during pregnancy is associated with asthma in 5-year-old-children. Am J Respir Crit Care Med. 2006 Sep 1;174(5):499-507.

9. Hijazi N, Abalkhail B, Seaton A. Diet and childhood asthma in a society in transition: a study in urban and rural Saudi Arabia. Thorax. 2000 Sep;55(9):775-9.

10. Troisi RJ, Willett WC, Weiss ST, Trichopoulos D, Rosner B, Speizer FE. A prospective study of diet and adult-onset asthma. Am J Respir Crit Care Med. 1995 May;151(5):1401-8.

11. Montaño Velázquez BB, Jáuregui-Renaud K, Bañuelos Arias Adel C, Ayala JC, Martínez MD, Campillo Navarrete R, et al. Vitamin E effects on nasal symptoms and serum specific IgE levels in patients with perennial allergic rhinitis. Ann Allergy Asthma Immunol. 2006 Jan;96(1):45-50.

12. Pearson PJ, Lewis SA, Britton J, Fogarty A. Vitamin E supplements in asthma: a parallel group randomised placebo controlled trial. Thorax. 2004 Aug;59(8):652-6.

13. Hlúbik P, Stř́tecká H. Antioxidants-clinical aspects. Cent Eur J Public Health. 2004 Mar;12 Suppl:S28-30.

14. Krajčovičová-Kudláčková M, Pauková V, Bačeková M, Dušinská M. Lipid peroxidation in relation to vitamin $\mathrm{C}$ and vitamin $\mathrm{E}$ levels. Cent Eur J Public Health. 2004 Mar;12(1):46-8.

15. Han SN, Wu D, Ha WK, Beharka A, Smith DE, Bender BS, et al. Vitamin E supplementation increases T helper 1 cytokine production in old mice infected with influenza virus. Immunology. 2000 Aug;100(4):487-93.

16. Malmberg KJ, Lenkei R, Petersson M, Ohlum T, Ichihara F, Glimelius $\mathrm{B}$, et al. A short-term dietary supplementation of high doses of vitamin E increases T helper 1 cytokine production in patients with advanced colorectal cancer. Clin Cancer Res. 2002 Jun;8(6):1772-8.

17. Li-Weber M, Giaisi M, Treiber MK, Krammer PH. Vitamin E inhibits IL-4 gene expression in peripheral blood T cells. Eur J Immunol. 2002 Sep;32(9):2401-8.

18. Wu D, Mura C, Beharka AA, Han SN, Paulson KE, Hwang D, et al. Age-associated increase in PGE2 synthesis and COX activity in murine macrophages is reversed by vitamin E. Am J Physiol. 1998 Sep;275(3 Pt 1):C661-8.

19. Roper RL, Brown DM, Phipps RP. Prostaglandin E2 promotes B lymphocyte Ig isotype switching to IgE. J Immunol. 1995 Jan;154(1):162170.

20. Fogarty A, Lewis S, Weiss S, Britton J. Dietary vitamin E, IgE concentrations, and atopy. Lancet. 2000 Nov 4;356(9241):1573-4.

21. Woods RK, Walters EH, Raven JM, Wolfe R, Ireland PD, Thien FC, et al. Food and nutrient intakes and asthma risk in young adults. Am J Clin Nutr. 2003 Sep;78(3):414-21.

22. Kompauer I, Demmelmair H, Koletzko B, Bolte G, Linseisen J, Heinrich J. Association of fatty acids in serum phospholipids with hay fever, specific and total immunoglobulin E. Br J Nutr. 2005 Apr;93(4):529-35.

23. McKeever TM, Lewis SA, Smit H, Burney P, Britton J, Cassano PA. Serum nutrient markers and skin prick testing using data from the Third National Health and Nutrition Examination Survey. J Allergy Clin Immunol. 2004 Dec;114(6):1398-402.

24. European Community Respiratory Health Survey II Steering Committee. The European Community Respiratory Health Survey II. Eur Respir J. 2002 Nov;20(5):1071-9.

25. Boeing H, Bohlscheid-Thomas S, Voss S, Schneeweiss S, Wahrendorf J; European Prospective Investigation into Cancer and Nutrition. The relative 
validity of vitamin intakes derived from a food frequency questionnaire compared to 24-hour recalls and biological measurements: results from the EPIC pilot study in Germany. Int J Epidemiol. 1997;26 Suppl 1:S82-90.

26. Bohlscheid-Thomas S, Hoting I, Boeing H, Wahrendorf J; European Prospective Investigation into Cancer and Nutrition. Reproducibility and relative validity of energy and macronutrient intake of a food frequency questionnaire developed for the German part of the EPIC project. Int J Epidemiol. 1997;26 Suppl 1:S71-81.

27. Bohlscheid-Thomas S, Hoting I, Boeing H, Wahrendorf J; European Prospective Investigation into Cancer and Nutrition. Reproducibility and relative validity of food group intake in a food frequency questionnaire developed for the German part of the EPIC project. Int J Epidemiol. 1997;26 Suppl 1:S59-70.

28. Kompauer I, Heinrich J, Wolfram G, Linseisen J. Association of caroten- oids, tocopherols and vitamin C in plasma with allergic rhinitis and allergic sensitisation in adults. Public Health Nutr. 2006 Jun;9(4):472-79.

29. Van Odijk J, Bengtsson U, Borres MP, Hulthen L, Ahlstedt S. Specific immunoglobulin E antibodies to peanut over time in relation to peanut intake, symptoms and age. Pediatr Allergy Immunol. 2004 Oct;15(5):442-8.

30. Veldink JH, Kalmijn S, Groeneveld GJ, Wunderink W, Koster A, de Vries $\mathrm{JH}$, et al. Intake of polyunsaturated fatty acids and vitamin E reduces the risk of developing amyotrophic lateral sclerosis. J Neurol Neurosurg Psychiatry. 2007 Apr;78(4):367-71. Erratum in: J Neurol Neurosurg Psychiatry. 2007 Jul;78(7):779.

31. Chan AC. Partners in defense, vitamin E and vitamin C. Can J Physiol Pharmacol. 1993 Sep;71(9):725-31.

Recivied September 15, 2008 Accepted in revised form February 18, 2009 